\title{
Neurodegenerative and Neuroprotective Effects of Tumor Necrosis Factor (TNF) in Retinal Ischemia: Opposite Roles of TNF Receptor 1 and TNF Receptor 2
}

\author{
Valerie Fontaine,, ${ }^{1}$ Saddek Mohand-Said, ${ }^{2}$ Noelle Hanoteau, ${ }^{2}$ Céline Fuchs, ${ }^{2}$ Klaus Pfizenmaier, ${ }^{1}$ and \\ Ulrich Eisel ${ }^{1}$ \\ 1/nstitute of Cell Biology and Immunology, University of Stuttgart, 70569 Stuttgart, Germany, and 2Laboratoire de \\ Physiopathologie Cellulaire et Moléculaire de la Rétine, Institut National de la Santé et de la Recherche Médicale EMI \\ 99-18, BP 426, 67091 Strasbourg, France
}

Tumor necrosis factor (TNF) is an important factor in various acute and chronic neurodegenerative disorders. In retinal ischemia, we show early, transient upregulation of TNF, TNF receptor 1 (TNF-R1), and TNF-R2 $6 \mathrm{hr}$ after reperfusion preceding neuronal cell loss. To assess the specific role of TNF and its receptors, we compared ischemia-reperfusion-induced retinal damage in mice deficient for TNF-R1, TNF-R2, or TNF by quantifying neuronal cell loss $8 \mathrm{~d}$ after the insult. Surprisingly, TNF deficiency did not affect overall cell loss, yet absence of TNF-R1 led to a strong reduction of neurodegeneration and lack of TNF-R2 led to an enhancement of neurodegeneration, indicative of TNF-independent and TNF-dependent processes in the retina, with TNF-R1 augmenting neuronal death and TNF-R2 promoting neuroprotection. Western blot analyses of retinas revealed that reduction of neuronal cell loss in TNFR1-/- animals correlated with the presence of activated Akt/ protein kinase $B(\mathrm{PKB})$. Inhibition of the phosphatidylinositol 3-kinase signaling pathway reverted neuroprotection in TNF$\mathrm{R} 1$-deficient mice, indicating an instrumental role of Akt/PKB in neuroprotection and TNF-R2 dependence of this pathway. Selective inhibition of TNF-R1 function may represent a new approach to reduce ischemia-induced neuronal damage, being potentially superior to strategies aimed at suppression of TNF activity in general.

Key words: Akt/PKB activation; neuronal TNF and TNF-R expression; retinal cell layers; ischemia; neuroprotection; knock-out mouse; immunohistology
Tumor necrosis factor (TNF) is upregulated in neurodegenerative disorders, such as multiple sclerosis and Parkinson's and Alzheimer's disease, as well as subsequent to brain trauma and ischemic injury (for review, see Shoshami et al., 1999). Retinal ischemia is a frequent complication in diabetic patients (CunhaVaz, 1998) and is believed to represent many aspects of other brain ischemic insults. Development of a brain ischemic lesion depends on the activation of many pathophysiological processes, dominating basal or concomitantly induced neuroprotective mechanisms (Maiese, 1998). Production and release of cytokines, particularly of TNF, is one of the early cellular events subsequent to an ischemic episode (Hangai et al., 1996; Shoshami et al., 1999). Because of its diverse bioactivities, it is presently not clear under which conditions TNF promotes beneficial or deleterious effects on neuronal tissues. An answer to this question might provide new strategies to prevent pathologies resulting from ischemia. The pleiotropic activities of TNF are mediated via two distinct receptors (for review, see Wajant and Scheurich, 2001). In vivo, TNF receptor 1 (TNF-R1) plays a prominent role in anti-

Received July 27, 2001; revised Jan. 11, 2002; accepted Jan. 23, 2002.

This work was supported by Hertie Foundation and Volkswagenstiftung to K.P. and U.E. and by Fédération Française des Aveugles. We are indebted to Horst Bluethmann (Hoffmann-La Roche, Basel, Switzerland) for providing TNF-R1-/and TNF-R2 - / - mice and to George Kollias (Pasteur Institute, Athens, Greece) for providing $\mathrm{TNF}-/-$ mice. We thank Nouredine Sadeg for assistance with the statistical analysis.

Correspondence should be addressed to Ulrich Eisel, Institute of Cell Biology and Immunology, University of Stuttgart, Allmandring 31, 70569 Stuttgart, Germany. E-mail: ulrich.eisel@po.uni-stuttgart.de.

Copyright (ㄷ) 2002 Society for Neuroscience $0270-6474 / 02 / 220001-07 \$ 15.00 / 0$ bacterial responses and in determining sensitivity to septic shock syndromes and is involved in the cellular organization of secondary lymphoid tissues (Pfeffer et al., 1993; Rothe et al., 1993; Kollias et al., 1999). The role of TNF-R2 was unclear until the membrane form of TNF was recognized as the physiological activator of this TNF receptor (Grell et al., 1995). Several studies now point to an important contribution of TNF-R2 to immune cell activation and endothelial functions, based on a cooperative action with TNF-R1 (Küsters et al., 1997; Lucas et al., 1997; Douni and Kollias, 1998; Kollias et al., 1999). However, the role of TNF and its two cognate receptors in the CNS is far from being understood. In vivo studies using different tools such as TNF neutralizing antibodies, soluble TNF receptors, and TNF and TNF-R knock-out and transgenic mouse models indicate an important function of TNF in inflammatory demyelinating diseases (Akassoglou et al., 1999) but have not allowed us to draw

This article is published in The Journal of Neuroscience, Rapid Communications Section, which publishes brief, peerreviewed papers online, not in print. Rapid Communications are posted online approximately one month earlier than they would appear if printed. They are listed in the Table of Contents of the next open issue of JNeurosci. Cite this article as: JNeurosci, 2002, 22:RC216 (1-7). The publication date is the date of posting online at www.jneurosci.org.

http://www.jneurosci.org/cgi/content/full/6253 
firm conclusions regarding the role of TNF produced in the CNS under trauma and ischemia (Cheng et al., 1994; Bruce et al., 1996; Dawson et al., 1996; Nawashiro et al., 1997; Lavine et al., 1998; Sherbel et al., 1999; Stahel et al., 2000). In the latter condition, the available data suggest that TNF may be capable of exerting opposite effects, which could depend on parameters such as the site, degree, and duration of the ischemic period, the amount of TNF production, the expression level of the two receptors, and the cellular environment of affected neurons. Using a model of retinal ischemia-reperfusion, we demonstrate involvement of the TNF/TNF-R system and opposing actions of the two TNF-Rs, with TNF-R1 aggravating neuronal damage and TNF-R2 promoting neuroprotection via an Akt/PKB signal pathway.

\section{MATERIALS AND METHODS}

Animals and reagents. Mice were kept according to federal regulations. TNF-R1-/- (Rothe et al., 1993) and TNF-R2-/- (Lucas et al., 1997) mice were from Horst Bluethmann (Hoffmann-La Roche, Basel, Switzerland), and TNF-/- (Moore et al., 1999) mice were from George Kollias (Pasteur Institute, Athens, Greece). Genotyping of TNF-R1 knock-out mice was performed using PCR with primers TNF-R1-2883 5'-CTCTCTTGTGATCAGCACTG-3' and Neo-34 5'-TCCCGCTTCAGTGACAACGTC-3', resulting in a $1 \mathrm{~kb}$ PCR product for the detection of the TNF-R1 null allele, and TNF-R1-2883 and TNF-R1-4938 5'-AGAAATCTCAAGACAATTCTCTGC-3', resulting in a $500 \mathrm{bp}$ fragment for the wild-type allele. Genotyping of the TNF-R2 knock-out mice was performed similarly as for TNF-R1 knock-out mice using TNF-R2-A primer 5' -CCTCTCATGCTGTCCCCGGATT-3' and NeoIL4 5'-GCGCATCGCCTTCTATCGCC-3', resulting in a PCR product of $700 \mathrm{bp}$ for the detection of the TNF-R2 null allele, and TNF-R2-A and TNF-R2-B 5'-AGCTCCAGGCACAAGGGCGGG-3', resulting in a $300 \mathrm{bp}$ fragment for the wild-type allele. TNF knock-out mice were kept in homozygosity. All mice were kept in a C57BL/6 background except for TNF-R1-/-, which were kept in a CD1xC57BL/6 background, with key experiments repeated in C57BL/6 background. Sensitivity of wild-type CD1xC57BL/6 and heterozygous TNF-R2 knock-out mice toward retinal ischemia was identical to that of $\mathrm{C} 57 \mathrm{BL} / 6$, as revealed from similar neuronal damage in all three retinal layers. Tropicamide and oxybuprocaine chlorhydrate were from Cibavision Ophthalmics (Toulouse, France). LY 294002 was from Calbiochem (Bad Soden, Germany). Rabbit anti-TNF (H-156), mouse anti-TNF-R2 (D-2), and mouse anti TNF-R1 (H-5) antibodies were from Santa Cruz Biotechnology (Santa Cruz, CA). Rabbit anti-Akt and mouse anti-phospho-Akt (Ser 473) antibodies were from New England Biolabs (Beverly, MA). Mouse anti- $\alpha$-tubulin antibody was from Sigma (St. Louis, MO). Goat anti-mouse IgG or anti-rabbit IgG conjugated to Alexa TM 488 were from Molecular Probes Europe BV (Leiden, The Netherlands). Peroxidase-conjugated antibodies were from Jackson ImmunoResearch Laboratories (West Grove, PA). The ECL detection kit was from Amersham Biosciences (Little Chalfont Buckinghamshire, UK). Pentobarbital and all other reagents used were purchased from Sigma (Deisenhofen, Germany).

Retinal ischemia-reperfusion. Retinal ischemia-reperfusion was performed as described (Hughes, 1990). Briefly, C57BL/6 [wild-type (wt)], TNF- / , TNF-R1 $-/-$, and TNF-R2 $-/-$ mice were anesthetized with an intraperitoneal injection of pentobarbital $(90 \mathrm{mg} / \mathrm{kg})$, the pupil was dilated with a drop of tropicamide, and a topical anesthesia was performed with oxybuprocaine chlorydrate. Retinal ischemia was induced in the left eye by increasing intraocular pressure to $150 \mathrm{~mm} \mathrm{Hg}$ through air injection into the anterior chamber for $45 \mathrm{~min}$. For immunohistology and immunoblotting, animals $(n=3)$ were killed after 6 or $24 \mathrm{hr}$ of reperfusion and immediately enucleated. For ischemic damage analysis, left eyes $(n=10)$ were removed after $8 \mathrm{~d}$ of reperfusion. For comparative purposes, non-ischemic retinas from each mouse strain were also investigated. LY 294002 was dissolved in DMSO at $5 \mathrm{mg} / \mathrm{ml}$ diluted to $10 \mu \mathrm{M}$ in $0.09 \% \mathrm{NaCl}$, and $1 \mu \mathrm{l}$ was injected intravitreally using an UltraMicroPump (type UMP2) equipped with a MicroSyringe Pump Controller (World Precision Instruments, Sarasota, FL).

Immunohistological analyses. Eyes were fixed for $1 \mathrm{hr}$ in $4 \%$ paraformaldehyde in $5 \%$ sucrose, cryoprotected in graded sucroses $(5,10$, and $20 \%$ ), and sectioned transversally at $10 \mu \mathrm{m}$ on a cryostat. Retinal sections were blocked for $1 \mathrm{hr}$ in a solution containing $10 \%$ normal goat serum,
$1 \%$ bovine serum albumin, and $0.5 \%$ Triton $\mathrm{X}-100$ in saline phosphate buffer, pH 7.4. Anti-TNF (1:200), anti-TNF-R1 (1:500), and antiTNF-R2 (1:500) primary antibodies were applied overnight at $4^{\circ} \mathrm{C}$. Staining was performed with Alexa TM 488-conjugated anti-mouse IgG or anti-rabbit IgG (1:1000; $1 \mathrm{hr}$ at room temperature). After washing, 4',6-diamidino-2-phenylindole dihydrochloride (DAPI) (1 $\mu \mathrm{g} / \mathrm{ml}$ in PBS) was applied for $10 \mathrm{~min}$. Retinas were examined by standard immunofluorescent microscopy. The specificity of each of the TNF/TNR antibodies was checked and verified by complete lack of staining in the respective knock-out strain.

Histological procedures and quantification of ischemic damage. Eyes were fixed for $24 \mathrm{hr}$ in $4 \%$ paraformaldehyde, dehydrated, and embedded in paraffin. Sections ( $3 \mu \mathrm{m}$ thick) containing the retina and crossing the optic nerve were stained with hematoxylin and eosin. Quantification of ischemic damage was assessed by measuring cell densities in each retinal layer according to Hughes (1990). They were expressed as a number of nuclei in a $30-\mu \mathrm{m}$-wide band for the outer and inner nuclear layers and as a number of nuclei in a $150-\mu \mathrm{m}$-wide band for the ganglion cell layer. Retinal sections were examined from digitalized images. For each retina, two areas located $800 \mu \mathrm{m}$ on both sides of the optic nerve were analyzed.

Protein extraction and Western blotting. After enucleation, retinas were quickly removed and collected on ice in lysis buffer $(50 \mathrm{~mm}$ Tris- $\mathrm{HCl}, \mathrm{pH}$ 7.4, $100 \mathrm{~mm} \mathrm{NaCl}, 2 \mathrm{~mm}$ EDTA, $1 \%$ Nonidet P-40, $1 \mathrm{~mm} \mathrm{NaF}, 1 \mathrm{~mm}$ $\mathrm{NaVO}_{4}, 10 \mu \mathrm{m}$ bestatin, $10 \mu \mathrm{g} / \mathrm{ml}$ leupeptin, $4 \mu \mathrm{g} / \mathrm{ml}$ aprotinin, and 0.5 mM PMSF). Twenty micrograms of proteins were separated by SDSPAGE on $10 \%$ gels and transferred on nitrocellulose membranes. Membrane blocking was performed $1 \mathrm{hr}$ at room temperature in 5\% skim milk in $0.1 \%$ Tween 20 (TBS-T) for anti-Akt, anti-tubulin antibodies, and in $5 \%$ BSA in TBS-T for anti-phospho-Akt antibody. For each set of samples, membranes were tested for the three antibodies studied using a stripping step between each. Primary antibodies were applied overnight at $4^{\circ} \mathrm{C}$ and were detected using peroxidase-conjugated secondary antibodies. Immunoblots were visualized using the ECL detection system.

Statistical analyses. Statistical analyses were performed as described (Hughes, 1990) according to the parametric method of the Student's $t$ test for unpaired series for each variable. After the variance analysis of each parameter, we performed Bartlett's test and compared the averages using Scheffe's $t$ test.

\section{RESULTS}

Expression of TNF and its receptors was examined in nonischemic and ischemic retinas of C57BL/6 mice. Retinal ischemia was induced by increasing intraocular pressure for $45 \mathrm{~min}$, and retinas were analyzed 6 and $24 \mathrm{hr}$ after reperfusion (Fig. 1). TNF was found mainly in the inner retina, with a stronger expression in the ganglion cell layer (GCL) compared with cells of the inner nuclear layer (INL). Within the latter, the staining was stronger in neurons such as amacrine cells close to the inner plexiform layer (IPL) (Fig. 1a, arrow). TNF expression was not found in the outer nuclear layer (ONL) composed of photoreceptors (Fig. $1 a, d)$. Significant increase in TNF expression was observed after $6 \mathrm{hr}$ of reperfusion, in particular in GCL and, to a lesser extend, in INL cells adjacent to the inner plexiform layer (IPL) (Fig. $1 b, e)$. At this time point, TNF was also detected within structures of the ONL resembling Müller glia processes (Fig. 1b,c). After 24 $\mathrm{hr}$, TNF expression in ganglion cells was back to control levels (Fig. 1c,f). These results extend previous data on induction of TNF after retinal ischemia (Hangai et al., 1996) and identify the cell layers capable of TNF expression.

TNF-Rs were below the immunohistochemical detection level in non-ischemic retina (Fig. $1 g, j$ ), which does not rule out an expression level sufficient to respond to a TNF stimulus. After 6 hr of reperfusion, cells localized in the inner INL and GCL showed a strong signal for both TNF receptor types. TNF-Rs were also found in the IPL and outer plexiform layer (OPL) as well as within structures of the ONL resembling Müller glia processes (Fig. 1h,k). Twenty-four hours after ischemiareperfusion, expression of TNF-Rs in all retinal layers was still discernable, but drastically reduced compared with $6 \mathrm{hr}$ (Fig. 1j,l). 

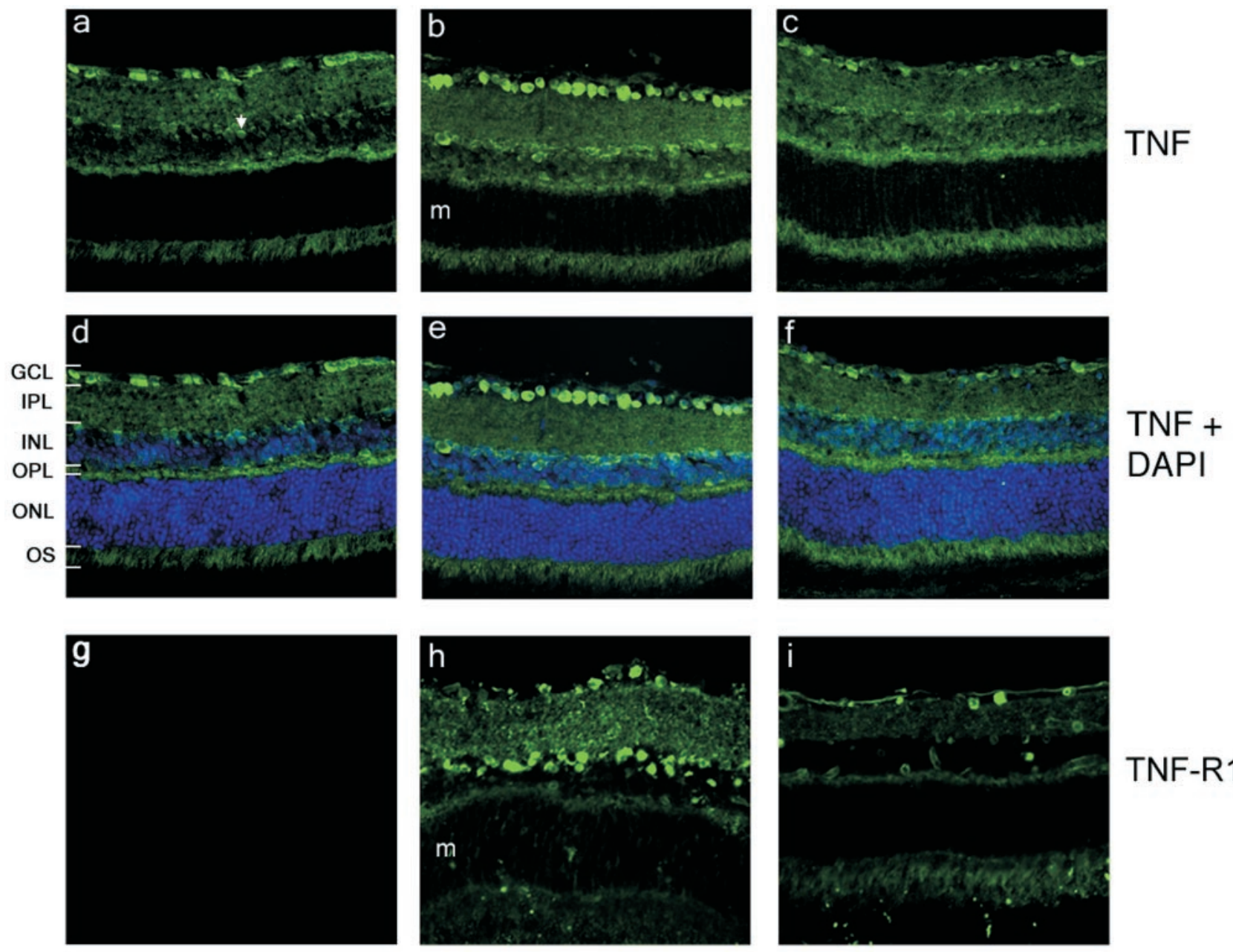

TNF-R1
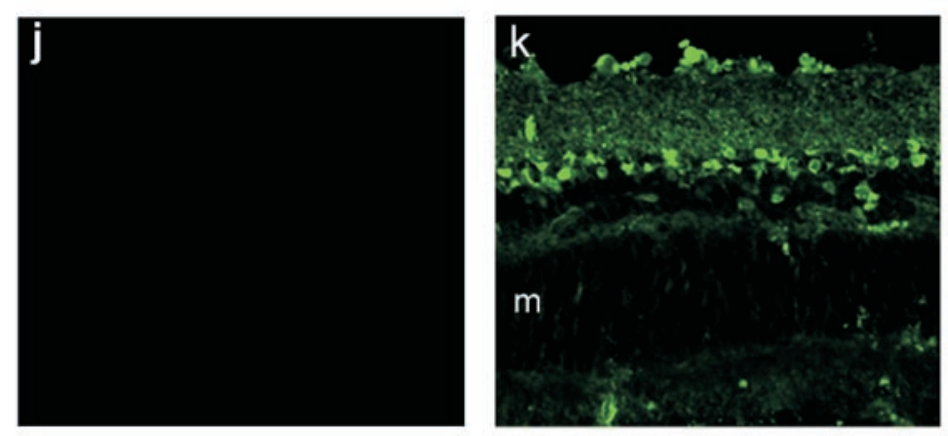

$\mathrm{m}$

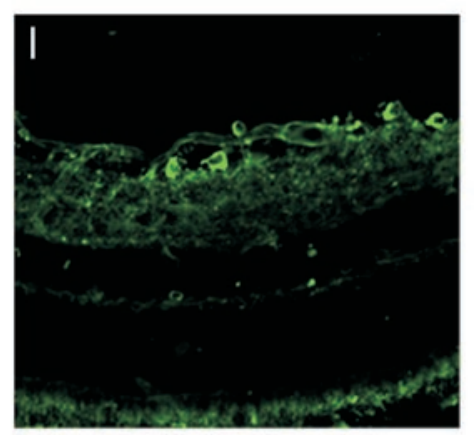

TNF-R2

no ischemia
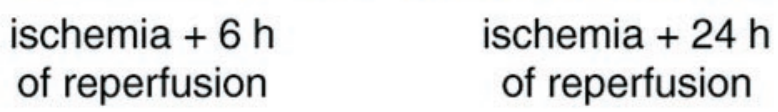

Figure 1. TNF and TNF-R upregulation after ischemia in the murine retina. Cryosections of retinas from untreated or ischemic C57BL/6 mice were analyzed by indirect immunofluorescence for TNF expression $(a-c)$ and costained with DAPI to detect nuclear layers $(d-f)$, or TNF-R1 $(g-i)$ and TNF-R2 ( $j-l)$ expression, respectively. $G C L$, Ganglion cell layer; $I P L$, inner plexiform layer; $I N L$, inner nuclear layer; $O P L$, outer plexiform layer; $O N L$, outer nuclear layer; $O S$, outer segment of photoreceptor cells; $m$, structures resembling Müller glia processes.

At this time point, only a few strongly staining cells were found in the GCL. These results show that TNF-Rs are present at a rather low expression level in the retina and that they are strongly, but transiently, upregulated after an ischemic insult.

Histological analyses of the neuronal damage were performed in wt and knock-out mice after $8 \mathrm{~d}$ of physiological reperfusion (Fig. 2). As a parameter of ischemia-induced pathology, neuronal cell death was determined by counting the nuclear densities in three distinct retinal layers: ONL, INL, and GCL. Control retinas from the various mouse strains did not present significant differences in cellular densities ranging between $91.4 \pm 7.2$ and $95.3 \pm 12$ for the ONL, between $29.5 \pm 3.7$ and $32.4 \pm 3.7$ for the INL, and between $18.5 \pm 2.2$ and $19.9 \pm 4.4$ for the GCL for the different strains of untreated animals (Fig. 3B). Ischemiareperfusion in wt mice induced a reduction of the whole retinal thickness, with a larger extent in the inner part of the retina, 

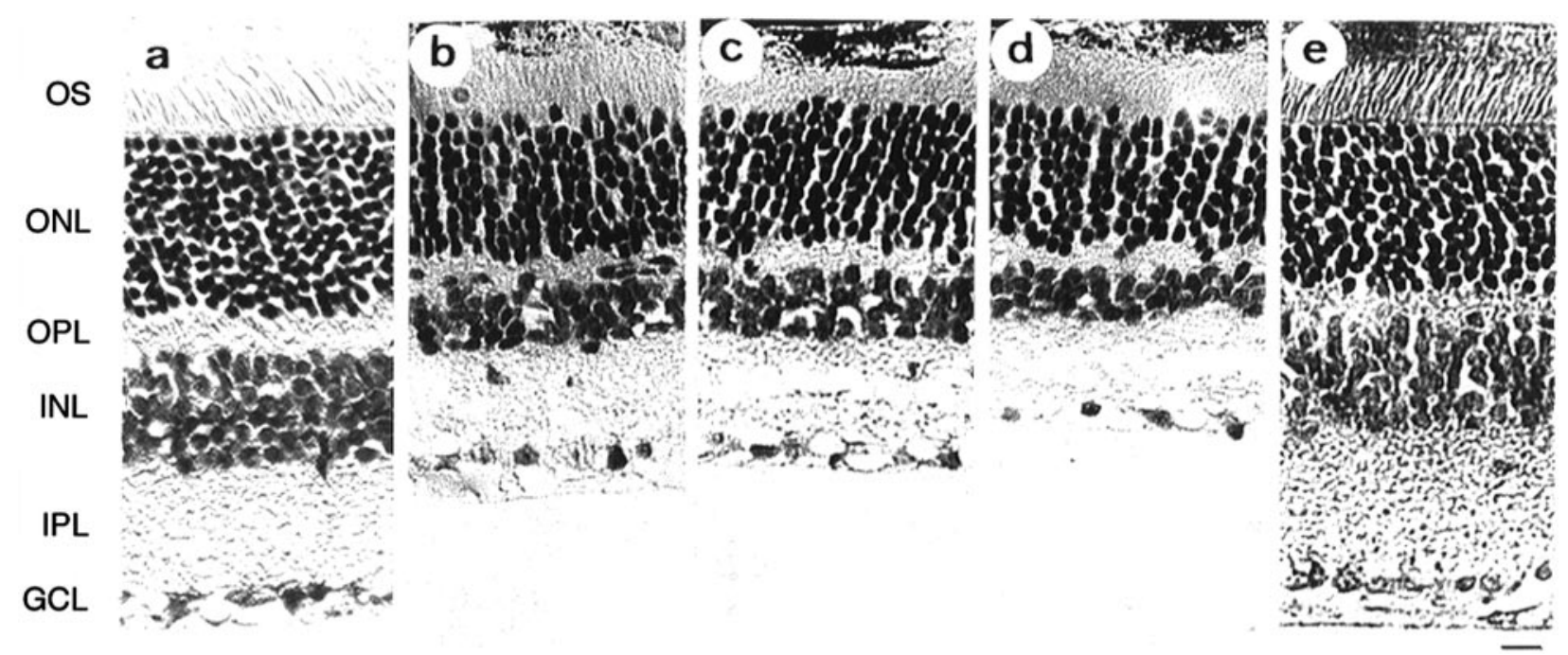

Figure 2. Histology of retinal sections. $a$, Wild-type (wt) control retina. $b-e$, Retinal sections $8 \mathrm{~d}$ after ischemia-reperfusion. Retinas from wt (b) and TNF- $/-(c)$ looked very similar. TNF-R2 $-/-$ retinas $(d)$ displayed a more degenerative morphology; TNF-R1-l- retinas $(e)$ were very well preserved. $O S$, Outer segments; $O P L$, outer plexiform layer; IPL, inner plexiform layer; GCL ganglion cell layer. Scale bar, $13 \mu \mathrm{m}$.

indicative of previous neurological damage (Fig. 2). This was confirmed by cell nuclei quantification, which showed significant $(p<0.001)$ neuronal death in all three retinal cell layers, with greater damage in the GCL $(36.7 \%$ reduction compared with controls) compared with INL (22.2\% reduction) and ONL (22\% reduction) (Fig. $3 A$ ), which is in accordance with previous studies showing that retinal ischemia affects all neuronal subtypes, with the GCL being most susceptible (Hughes, 1990).

After ischemia, each of the three mutant mouse strains displayed a distinct pattern of cell degeneration (Fig. 3A,B). In comparison with wt mice, TNF-R1-/- mice displayed no neuronal loss in the INL ( 0 vs $22.2 \%)$ and a significantly reduced damage in ONL (12.3 vs $22 \%$ ) and GCL (15 vs $36.7 \%)$. Unexpectedly, retinas from TNF-R2-/- mice were more strongly affected by ischemia than those from wt mice, showing an increased neuronal loss in all three cellular layers (ONL, 37.8 vs $22 \%$; INL, 37 vs 22.2\%; GCL, 51.4 vs $36.7 \%$ ), suggesting a neuroprotective role of TNF-R2 for retinal neurons. Interestingly, in mice with a deletion of the TNF gene itself, the overall neuronal damage after retinal ischemia was not significantly different from wt mice (Fig. $3 A, B$ ).

To identify potential mechanisms involved in TNF-R2mediated neuroprotection, we investigated the presence and activation of the protein kinase Akt/PKB, which has previously been shown to participate in TNF-induced anti-apoptotic pathways (Ozes et al., 1999). Akt/PKB was uniformly detectable in lysates of ischemic retinas of all mouse strains investigated (Fig. 4, top panel). The protein levels did not change after ischemia. However, phosphorylated and thus activated Akt/PKB was detected exclusively in ischemic retinal extracts from TNF-R1-/animals after $6 \mathrm{hr}$ of reperfusion, but not in extracts from wildtype or TNF-/- or TNF-R2-/- animals (Fig. 4, middle panel), indicative of a TNF/TNF-R2 dependence of Akt/PKB activation in this tissue. After $24 \mathrm{hr}, \mathrm{Akt} / \mathrm{PKB}$ phosphorylation was no longer detectable in the TNF-R1-/- mouse or in any other of the mouse strains tested (data not shown). The importance of Akt/PKB activation for protection from ischemic damage was shown by intravitreal application of the phosphatidylinositol 3-phosphate kinase inhibitor LY294002 in TNF-R1-/- mice, resulting in marked enhancement of retinal damage (Fig. $3 B$ ).

\section{DISCUSSION}

We addressed the multifactorial nature of ischemic lesions and provide new mechanistic insights with respect to the contribution of TNF, which is induced after ischemia in the retina (Fig. 1) and promotes at the same time neurodegeneration and neuroprotection. We present, for the first time, experimental evidence for an antagonistic function of the two TNF-Rs during ischemia-reperfusion damage of retinal neurons. In a TNF-R2-deficient situation, TNF was found to aggravate cell death in three different retinal layers. This indicates not only that TNF-R1 signaling is sufficient for TNF-mediated retinal damage, but further suggests that the observed enhancement of pathology is probably caused by an unbalanced activation of TNF-R1. The importance of TNF-R1 in mediating neuronal cell death in vivo is underlined by the absence (INL) or the significant reduction (ONL, GCL) of cell death in the different retinal layers of TNF-R1-/- mice. Furthermore, the reduced lesion size in TNF-R1-/- as compared with $\mathrm{TNF}-/-$ mice, the latter presenting with damage similar to that of wild-type animals, reveals (1) a TNF -independent component in ischemia-induced lesions and (2) a requirement for TNF-R2 signals antagonizing this TNFindependent neuronal damage, resulting in full (INL) or at least substantial protection of the affected neuronal populations. Because the neuroprotective activity of TNF via TNF-R2 became apparent only in mice lacking TNF-R1, we suggest that TNFmediated protection is blurred by concomitantly ongoing degenerative signals emanating from TNF-R1.

Our finding of a TNF-independent pathway of retinal degeneration is not unexpected, because several other members of this large cytokine family have been implicated in neurodegenerative processes. First, Lymphotoxin $\alpha$ binds to TNF-R1 (Wajant et al., 1998) and thus could potentially substitute for TNF in retinal TNF-R1 signal pathways. However, at present the role of Lymphotoxin $\alpha$ in neurodegenerative diseases is controversial (Suen et al., 1997; Sean Riminton et al., 1998). Second, two recent studies showed, in addition to TNF, involvement of Fas ligand (Martin-Villalba et al., 1999, 2001) and TRAIL in brain ischemia induced by arterial occlusion (Martin-Villalba et al., 1999). Although for the latter two members of the TNF family an involve- 

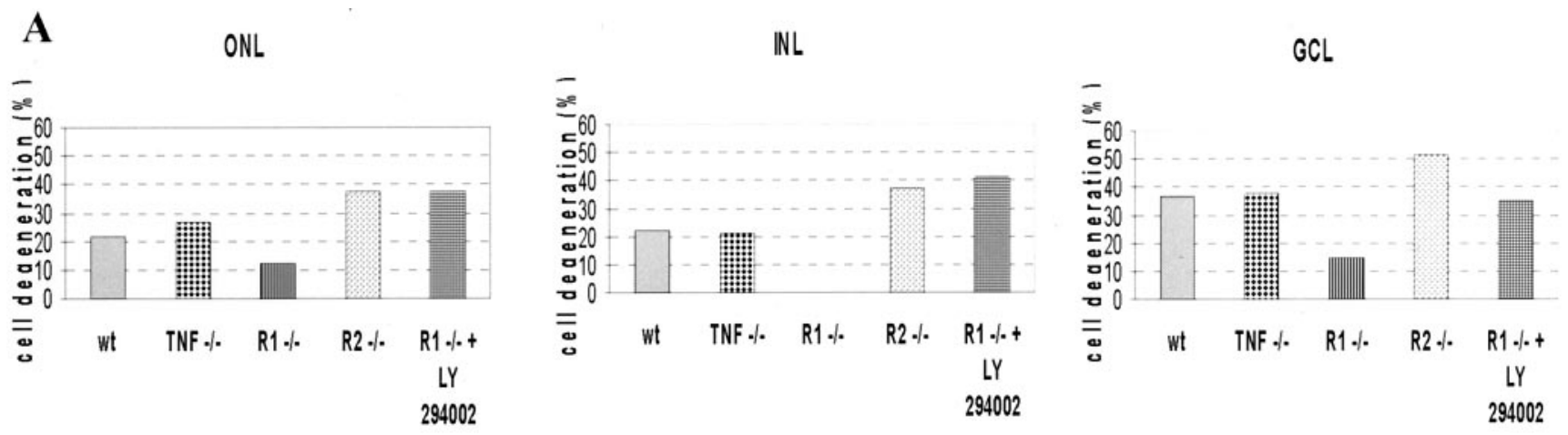

B

\section{Statistical analyses of histological sections}

\begin{tabular}{|c|c|c|c|c|c|c|c|c|c|c|c|c|c|c|c|}
\hline \multicolumn{2}{|c|}{$\begin{array}{l}\text { Mouse } \\
\text { strain }\end{array}$} & \multicolumn{2}{|c|}{ C57BL/6 (wt) } & \multicolumn{2}{|c|}{$\begin{array}{c}\text { CD1 x } \\
\text { C57BL/6 }\end{array}$} & \multicolumn{2}{|c|}{$\mathrm{R} 2+1-$} & \multicolumn{2}{|c|}{ TNF -/- } & \multicolumn{2}{|c|}{ R1 I- } & \multicolumn{2}{|c|}{ R2 - } & \multicolumn{2}{|c|}{$\begin{array}{c}\text { R1 -l-+ } \\
\text { LY } 294002\end{array}$} \\
\hline & & $c$ & $i$ & $c$ & $i$ & $c$ & $i$ & $c$ & $i$ & $c$ & $i$ & $c$ & $i$ & $c$ & $i$ \\
\hline \multirow{3}{*}{ ONL } & $\begin{array}{c}\text { mean } \pm \\
S D\end{array}$ & $\begin{array}{c}92.5 \pm \\
8.3\end{array}$ & $\begin{array}{l}72 \pm \\
6.2\end{array}$ & $\begin{array}{c}93.4 \pm \\
5.6\end{array}$ & $\begin{array}{c}70.8 \pm \\
6.2\end{array}$ & $\begin{array}{c}90.4 \pm \\
7.2\end{array}$ & $\begin{array}{c}69.5 \pm \\
4.9\end{array}$ & $\begin{array}{c}95.3 \pm \\
12\end{array}$ & $\begin{array}{c}69.9 \pm \\
4.1\end{array}$ & $\begin{array}{c}92.8 \pm \\
8.2\end{array}$ & $\begin{array}{c}81.4 \pm \\
4.4\end{array}$ & $\begin{array}{c}91.4 \pm \\
7.2\end{array}$ & $\begin{array}{c}57.8 \\
16.2\end{array}$ & $\begin{array}{c}89 \\
1.6\end{array}$ & $\begin{array}{c}55.4 \pm \\
6.4\end{array}$ \\
\hline & 1 & \multirow{2}{*}{\multicolumn{2}{|c|}{ Na*k }} & \multicolumn{2}{|c|}{$\alpha \ldots$} & \multicolumn{2}{|c|}{ 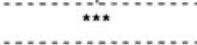 } & \multicolumn{2}{|c|}{ 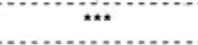 } & & & \multicolumn{2}{|c|}{$\ldots$} & \multicolumn{2}{|c|}{$\cdots$} \\
\hline & 2 & & & \multicolumn{2}{|c|}{ NS } & \multicolumn{2}{|c|}{ NS } & \multicolumn{2}{|c|}{ NS } & & & \multicolumn{2}{|c|}{$\cdots$} & \multicolumn{2}{|c|}{$\cdots$} \\
\hline \multirow{3}{*}{ INL } & $\begin{array}{c}\text { mean } \pm \\
S D\end{array}$ & $\begin{array}{c}32.4 \pm \\
3.7\end{array}$ & $\begin{array}{c}25.2 \pm \\
5.1\end{array}$ & $\begin{array}{c}31.8 \pm \\
2.2\end{array}$ & $\begin{array}{c}25.8 \pm \\
4.2\end{array}$ & $\begin{array}{c}30.8 \pm \\
2.9\end{array}$ & $\begin{array}{c}25.5 \pm \\
4.3\end{array}$ & $\begin{array}{c}32.2 \pm \\
3.3\end{array}$ & $\begin{array}{c}25.4 \pm \\
3.1\end{array}$ & $\begin{array}{c}29.5 \pm \\
3.7\end{array}$ & $\begin{array}{c}29.6 \pm \\
3.7\end{array}$ & $\begin{array}{c}30.3 \pm \\
2.9\end{array}$ & $\begin{array}{c}19.1 \pm \\
3.4\end{array}$ & $\begin{array}{c}30.3 \pm \\
0.5\end{array}$ & $\begin{array}{c}17.8+ \\
4.9\end{array}$ \\
\hline & 1 & \multirow{2}{*}{\multicolumn{2}{|c|}{ **** }} & \multirow{2}{*}{\multicolumn{2}{|c|}{ NS }} & \multirow{2}{*}{\multicolumn{2}{|c|}{ NS }} & \multirow{2}{*}{\multicolumn{2}{|c|}{ NS }} & \multirow{2}{*}{\multicolumn{2}{|c|}{ NS }} & \multirow{2}{*}{\multicolumn{2}{|c|}{ 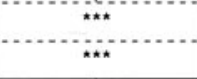 }} & \multirow{2}{*}{\multicolumn{2}{|c|}{$\ldots * *$}} \\
\hline & 2 & & & & & & & & & & & & & & \\
\hline \multirow{3}{*}{ GCL } & $\begin{array}{c}\text { mean } \pm \\
S D\end{array}$ & $\begin{array}{c}19.9 \pm \\
4.4\end{array}$ & $\begin{array}{c}12.6 \pm \\
2.0\end{array}$ & $\begin{array}{c}19.0 \pm \\
3.2\end{array}$ & $\begin{array}{c}11.9 \pm \\
2.5\end{array}$ & $\begin{array}{c}18.9 \pm \\
2.7\end{array}$ & $\begin{array}{c}12.5 \pm \\
2.2\end{array}$ & $\begin{array}{c}19.4= \\
3.4\end{array}$ & $\begin{array}{c}12.1 \pm \\
2.3\end{array}$ & $\begin{array}{c}18.7 \pm \\
4.1\end{array}$ & $\begin{array}{c}15.9 \pm \\
2.1\end{array}$ & $\begin{array}{c}18.5 \pm \\
2.2\end{array}$ & $\begin{array}{c}9.0 \pm \\
3.5\end{array}$ & $\begin{array}{c}20.3 \pm \\
0.5\end{array}$ & $\begin{array}{c}13.2 \pm \\
2.1\end{array}$ \\
\hline & 1 & & & \multicolumn{2}{|c|}{ nat. } & \multicolumn{2}{|c|}{ 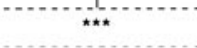 } & \multicolumn{2}{|c|}{ *n* } & \multicolumn{2}{|c|}{ NS } & \multicolumn{2}{|c|}{ nkn } & \multicolumn{2}{|c|}{$\ldots *$} \\
\hline & 2 & & & \multicolumn{2}{|c|}{ NS } & & & & & & & & & & \\
\hline
\end{tabular}

Figure 3. Differential sensitivity of TNF-/- and TNFR - / - mice to retinal ischemia-reperfusion-damage. $A$, Neuronal degeneration in different retinal cell layers. $O N L$, outer nuclear layer; $I N L$, inner nuclear layer; $G C L$, ganglion cell layer. Data are expressed as percentage reduction in neuronal cell number after $8 \mathrm{~d}$ of reperfusion compared with non-ischemic animals of the same mouse strain. $B$, Quantitative and statistical analyses of neuronal cell densities. A neuronal cell count was performed on histological sections of ischemic retinas after $8 \mathrm{~d}$ of reperfusion as well as on control retinas. Treatment with LY294002 in solution alone without ischemia had no effect on the retinal cell numbers $(G C L, 19.7 \pm 1.5 ; I N L, 28.3 \pm 2.1 ; O N L, 90.3 \pm$ 4.7). For the ONL and INL, $2.5 \%$ of the total retinas were counted; for the GCL, $12.5 \%$ were counted. Values presented are expressed as the mean \pm SD of the number of nuclei per field $(n=20)$. Statistical analyses: (1) control (c) compared with ischemia $(i)$ in each group tested; (2) $i$ compared with $i$ in $w t$ mice. $N S$, Not significant. * $p<0.05 ;{ }^{* *} p<0.01 ; * * * p<0.001$.

ment in retinal degeneration remains to be verified experimentally, the TNF-independent damage observed in the present study is in accordance with a contribution of one or both of these pro-apoptotic cytokines.

An important question relates to the immediate cellular targets of the antagonistic TNF actions, i.e., neuronal versus nonneuronal cells. This is of particular relevance because effects on the vasculature are now considered essential to initiate ischemic tissue damage (for review, see Petty and Wettstein, 2001). In fact, our data do not rule out TNF actions on the vasculature, in particular those contributing to tissue damage. However, the wide staining for both TNF-Rs in several retinal neuronal layers indicates that neuronal cells are involved and potentially direct targets of TNF action. In support of this reasoning, at least for the neuroprotective function of TNF, a direct and TNF-R2dependent action on human neuronal cells has been shown recently in vitro using an antisense oligonucleotide approach to downregulate TNF-R2 expression (Shen et al., 1997). Our in vitro studies with primary cortical neurons from TNF-R1 and TNF-R2 knock-out mice now corroborate these findings and clearly show a direct TNF action on these primary murine neurons, with TNF-R1-deficient, but not TNF-R2-deficient, neurons being protected from glutamate-induced excitotoxicity (L. Marchetti and U. Eisel, unpublished data). These data provide further evidence for the differential role of the two TNF-Rs expressed on neuronal cells.

Concerning the potential mechanisms involved in TNF-R2mediated neuroprotection, our data point to an important function of protein kinase Akt/PKB. Akt/PKB has been reported to play an important role in cell survival pathways by interfering at several levels with pro-apoptotic signals (Yuan and Yankner, 2000) and to be activated in response to TNF (Ozes et al., 1999). $\mathrm{Akt} / \mathrm{PKB}$ is supposed to be critical in protection from reperfusion injury (Yellon and Baxter, 1999) and is known to mediate, at least in part, the effect of brain-derived neurotrophic factor, one of the most effective survival factors in the retina (Klöcker et al., 2000). The failure of $\mathrm{TNF}-/-$ mice to stimulate Akt/PKB kinase activity and the kinetics of TNF/TNF-R induction after ischemia, which coincides with retinal Akt/PKB phosphorylation, supports TNF dependence on Akt/PKB activation in reti- 


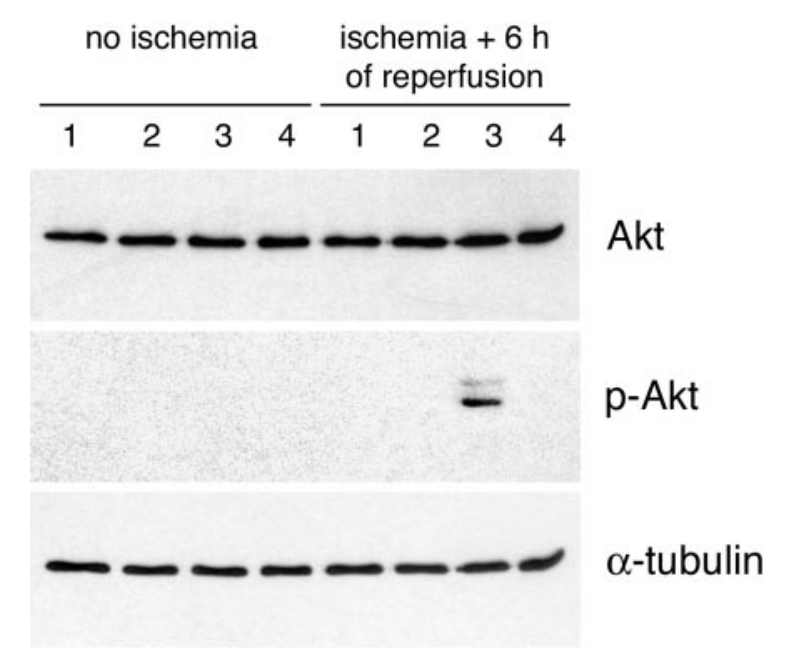

Figure 4. Phosphorylated Akt/PKB is present in the retina of TNF$\mathrm{R} 1-/-$ mice subsequent to an ischemic insult. Retinas from C57BL/6 wt (lane 1), TNF-/- (lane 2), TNF-R1-/- (lane 3), and TNF-R2-/- (lane 4 ), without or with ischemia, were analyzed by Western blotting for Akt/PKB (total protein, top panel) and reprobed for phosphorylated Akt (middle panel). The results were normalized by reprobing with antibodies specific for $\alpha$-tubulin (bottom panel).

nal neurons in vivo. These findings are in accordance with the proposed role of Akt/PKB in neuroprotection (Yellon and Baxter, 1999; Klöcker et al., 2000; Yuan and Yankner, 2000). Very recent data show that $\mathrm{TNF}$ protects, via $\mathrm{Akt} / \mathrm{PKB}$ activation, axotomized retinal ganglion cells from retrograde cell death, and therefore they fully support our findings (Diem et al., 2001). Our data also show that in retinal neurons, activation of $\mathrm{Akt} / \mathrm{PKB}$ is dependent on a TNF-R2 signal pathway. We further suggest that lack of detectable Akt/PKB activation in the retina of wt mice could reflect a repression of this TNF-R2-dependent pathway by TNF-R1-mediated signals.

A neuroprotective role of TNF in a model of focal cerebral ischemia was already suggested previously from data with mice double-deficient for both TNF receptors (Bruce et al., 1996). At variance with our data, however, is a subsequent study from the same laboratory analyzing hippocampal ischemia-reperfusion damage, indicating a TNF-R1 dependence of the neuroprotective effect (Gary et al., 1998). The two models, retinal and focal cerebral ischemia, differ not only with respect to methodological aspects and time course of development of the lesions, but probably as important, they differ with respect to cellular composition in the regions affected by the ischemic insult. In the retinal ischemia model, we have obtained evidence that the distinct neuronal cell populations present in the various retinal layers differ with respect to sensitivity to the ischemic insult and expression of (Fig. 1) and protection by TNF/TNF-R2 signals (Fig. 3). Therefore, the opposite role of TNF-R1 determined in the two models, disease promoting in the case of retinal ischemia (this paper) and disease amelioration in the case of hippocampal damage (Gary et al., 1998), may reflect this different cellular composition in the targeted areas and a differential cellular response to TNF exposition. However, very recent data obtained in an experimental autoimmune encephalomyelitis model also suggest an antagonistic action of the two TNF receptors (Kassiotis and Kollias, 2001), which is in full accordance with our data obtained in retinal ischemia and strengthen our hypothesis of a differential role of the two TNF receptors in vivo. On the basis of our data, we propose that blocking TNF-R1 function and selectively activating TNF-R2 could represent a promising new approach in preventing irreversible neuronal loss by ischemic insults, at least in the retina.

\section{REFERENCES}

Akassoglou K, Bauer J, Kassiotis G, Lassmann H, Kollias G, Probert L (1999) Transgenic models of TNF induced demyelination. Adv Exp Med Biol 468:245-259.

Bruce AJ, Boling W, Kindy MS, Peschon J, Kraemer PJ, Carpenter MK, Holtsberg FW, Mattson MP (1996) Altered neuronal and microglial responses to excitotoxic and ischemic brain injury in mice lacking TNF receptors. Nat Med 2:788-794.

Cheng B, Christakos S, Mattson MP (1994) Tumor necrosis factors protect neurons against metabolic-excitotoxic insults and promote maintenance of calcium homeostasis. Neuron 12:139-153.

Cunha-Vaz J (1998) Lowering the risk of visual impairment and blindness. Diabet Med 15[Suppl 4]:47-50.

Dawson DA, Martin D, Hallenbeck JM (1996) Inhibition of tumor necrosis factor-alpha reduces focal cerebral ischemic injury in the spontaneously hypertensive rat. Neurosci Lett 218:41-44.

Diem R, Meyer R, Weishaupt JH, Bähr M (2001) Reduction of potassium currents and phosphatidylinositol 3-kinase-dependent Akt phosphorylation by tumor necrosis factor- $\alpha$ rescues axotomized retinal ganglion cells from retrograde cell death in vivo. J Neurosci 21:2058-2066.

Douni E, Kollias G (1998) A critical role of the p75 tumor necrosis factor receptor (p75TNF-R) in organ inflammation independent of TNF, lymphotoxin alpha, or the p55TNF-R. J Exp Med 188:1343-1352.

Gary DS, Bruce-Keller AJ, Kindy MS, Mattson MP (1998) Ischemic and excitotoxic brain injury is enhanced in mice lacking the p55 tumor necrosis factor receptor. J Cereb Blood Flow Metab 18:1283-1287.

Grell M, Wajant H, Löhden M, Maxeiner B, Georgopoulos S, Kollias G, Lesslauer W, Pfizenmaier K, Scheurich P (1995) The transmembrane form of tumor necrosis factor (TNF) is the prime activating ligand of the $80 \mathrm{kDa}$ TNF receptor. Cell 83:793-802.

Hangai M, Yoshimura N, Honda Y (1996) Increased cytokine gene expression in rat retina following transient ischemia. Ophthal Res 28:248-254.

Hughes WF (1990) Quantification of the ischemic damage in the rat retina. Exp Eye Res 53:573-582.

Kassiotis G, Kollias G (2001) Uncoupling the proinflammatory from the immunosuppressive properties of tumor necrosis factor (TNF) at the p55 TNF receptor level. Implications for pathogenesis and therapy of autoimmune demyelination. J Exp Med 193:427-434.

Klöcker N, Kermer P, Weishaupt JH, Labes M, Ankerhold R, Bähr M (2000) Brain-derived neurotrophic factor-mediated neuroprotection of adult rat retinal ganglion cells in vivo does not exclusively depend on phosphatidyl-inositol-3'-kinase/protein kinase B signaling. J Neurosci 20:6962-6967.

Kollias G, Douni E, Kassiotis G, Kontoyiannis D (1999) On the role of tumor necrosis factor and receptors in models of multi-organ failure, rheumatoid arthritis, multiple sclerosis and inflammatory bowel disease. Immunol Rev 169:175-194.

Küsters S, Tiegs G, Alexopoulou L, Pasparakis M, Douni E, Kunstle G, Bluethmann H, Wendel A, Pfizenmaier K, Kollias G, Grell M (1997) In vivo evidence for a functional role of both tumor necrosis factor (TNF) receptors and transmembrane TNF in experimental hepatitis. Eur J Immunol 27:2870-2875.

Lavine SD, Hofman FM, Zlokovic BV (1998) Circulating antibodies against tumor necrosis factor-alpha protects rat brain from reperfusion injury. J Cereb Blood Flow Metab 18:52-58.

Lucas R, Juillard P, Decoster E, Redard M, Burger M, Donati Y, Giroud C, Monso-Hinard C, DeKesel T, Burman WA, Moore MW, Dayer JM, Fiers W, Bluethmann H, Grau GE (1997) Crucial role of tumor necrosis factor (TNF) receptor 2 and membrane-bound TNF in experimental cerebral malaria. Eur J Immunol 27:1719-1725.

Maiese K (1998) From the bench to the bedside: the molecular management of cerebral ischemia. Clin Neuropharmacol 21:1-7.

Martin-Villalba A, I Herr, Jeremias I, Hahne M, Brandt R, Vogel J, Schenkel J, Herdegen T, Debatin K-M (1999) CD95 ligand (Fas-L/ APO-1L) and tumor necrosis factor-related apoptosis-inducing ligand mediate ischemia-induced apoptosis in neurons. J Neurosci 19:3809-3817.

Martin-Villalba A, Hahne M, Kleber S, Vogel J, Falk W, Schenkel J, Krammer PH (2001) Therapeutic neutralization of CD95-ligand and TNF attenuates brain damage in stroke. Cell Death Differ 8:679-686. Moore RJ, Owens DM, Stamp G, Arnott C, Burke F, East N, Holdsworth H, Turner L, Rollins B, Pasparakis M, Kollias G, Balkwill F (1999) Mice deficient in tumor necrosis factor-alpha are resistant to skin carcinogenesis. Nat Med 5:828-831.

Nawashiro H, Martin D, Hallenbeck JM (1997) Neuroprotective effects 
of TNF binding protein in focal cerebral ischemia. Brain Res $778: 265-271$.

Ozes ON, Mayo LD, Gustin JA, Pfeffer SR, Pfeffer LM, Donner DB (1999) NF-kappaB activation by tumour necrosis factor requires the Akt serine-threonine kinase. Nature 401:82-85.

Petty MA, Wettstein JG 2001 Elements of cerebral microvascular ischaemia. Brain Res Rev 36:23-34.

Pfeffer K, Matsuyama T, Kunidg TM, Wakeham A, Kishihara K, Shahinian A, Wiegmann K, Ohashi PS, Krönke M, Mak TW (1993) Mice deficient for the $55 \mathrm{kd}$ tumor necrosis factor receptor are resistant to endotoxic shock, yet succumb to $L$. monocytogenes infection. Cell 73:457-467.

Rothe J, Lesslauer W, Lotscher H, Lang Y, Koebel P, Althage A, Zinkernagel R, Steinmetz M, Bluethmann H (1993) Mice lacking the tumour necrosis factor receptor 1 are resistant to TNF-mediated toxicity but highly susceptible to infection by Listeria monocytogenes. Nature 364:798-802.

Sean Riminton D, Korner H, Strickland DH, Lemckert FA, Pollard JD, Sedgwick JD (1998) Challenging cytokine redundancy: inflammatory cell movement and clinical course of experimental autoimmune encephalomyelitis are normal in lymphotoxin-deficient, but not tumor necrosis factor-deficient, mice. J Exp Med 187:1517-1528.

Shen Y, Li R, Shiosaki K (1997) Inhibition of p75 tumor necrosis factor receptor by antisense oligonucleotides increases hypoxic injury and $\beta$-amyloid toxicity in human neuronal cell line. J Biol Chem 272:3550-3553.
Sherbel U, Raghupathi R, Nakamura M, Saatman KE, Trojanowski JQ, Neugebauer E, Marino MW, McIntosh TK (1999) Differential acute and chronic responses of tumor necrosis factor-deficient mice to experimental brain injury. Proc Natl Acad Sci USA 96:8721-8726.

Shoshami E, Ginis I, Hallenbeck JM (1999) Dual role of tumor necrosis factor in brain injury. Cytokine Growth Factor Rev 10:119-130.

Stahel PF, Shoshami E, Younis FM, Kariya K, Otto VI, Lenzlinger PM, Grosjean MB, Eugster HP, Trentz O, Kossmann T, Morganti-Koss MC (2000) Experimental closed head injury: analysis of neurological outcome, blood-brain barrier dysfunction, intracranial neutrophil infiltration, and neuronal cell death in mice deficient in genes for proinflammatory cytokines. J Cereb Blood Flow Metab 20:369-380.

Suen WE, Bergman CM, Hjelmstrom P, Ruddle NH (1997) A critical role for lymphotoxin in experimental allergic encephalomyelitis. J Exp Med 186:1233-1240.

Wajant H, Scheurich P (2001) Tumor necrosis factor receptor associated factor (TR AF) 2 and its role in TNF signaling. Int J Biochem Cell Biol 33:19-32.

Wajant H, Pfeffer K, Pfizenmaier K, Scheurich P (1998) Tumor necrosis factor in 1998. Cytokine Growth Factor Rev 9:297-302.

Yellon DM, Baxter GF (1999) Reperfusion injury revisited: is there a role for growth factor signalling in limiting lethal reperfusion injury? Trends Cardiovasc Med 9:245-249.

Yuan J, Yankner BA (2000) Apoptosis in the nervous system. Nature 407:802-809. 